\title{
A GPR-Based Test Study on the Influencing Factors of the Dielectric Constant of Cement-Stabilized Macadam Bases
}

\author{
Xue Han $\left({ }^{1}\right.$ Shifei Cao, ${ }^{2}$ and Hanhui $\mathrm{He}^{1}$ \\ ${ }^{1}$ School of Civil and Architectural Engineering, Hunan University of Arts and Science, Changde 415000, China \\ ${ }^{2}$ School of Architectural Engineering, Heilongjiang University of Science and Technology, Harbin 150022, China \\ Correspondence should be addressed to Xue Han; hanxue69@163.com
}

Received 30 September 2021; Accepted 5 February 2022; Published 23 February 2022

Academic Editor: Francesco Colangelo

Copyright (c) 2022 Xue Han et al. This is an open access article distributed under the Creative Commons Attribution License, which permits unrestricted use, distribution, and reproduction in any medium, provided the original work is properly cited.

Dielectric constant is an important parameter for the nondestructive test of cement stabilized macadam base (CSMB) on road by ground-penetrating radar (GPR). However, few studies have been reported on the quantitative relationship between the dielectric constant and the compaction degree, strength indicators, and influencing factors of CSMB. To address the problem, groups of CSMB specimens, which were different in gradation of aggregate (fine or coarse), compaction degree, and curing time, were made and tested for dielectric constant and influencing factors with the help of the Swedish MALA GPR. The relationship between the dielectric constant of CSMB and the influencing factors such as the compaction degree, moisture content, percent residues of aggregate on the sieve of maximum particle size and curing age, and the relationship between the dielectric constant and the unconfined compressive strength were investigated based on several test data and theoretical analysis. The major findings are as follows. There is a good logarithmic correlation between the dielectric constant and the compaction degree of CSMB, and quantitative functions have been established. There is a good linear relationship between the dielectric constant and the unconfined compressive strength of CSMB, and quantitative functions have been established. A comprehensive equation between the dielectric constant of CSMB and the influencing factors such as the compaction degree, moisture content, percent residues of aggregate on the sieve of maximum particle size, and curing age has been established and validated with high significance and small error. The findings are a theoretical basis for the application of GPR to the test and quality assessment of CSMB on roads.

\section{Introduction}

Ground-penetrating radar (GPR) has been widely used in geophysical exploration and construction engineering in many countries [1-6], especially in nondestructive tests of structural layers such as cement stabilized macadam base (CSMB) in road engineering [7-9]. The compaction degree and strength of the cement stabilized macadam base, which is an important layer of the road base, are major indicators of quality of road construction. During construction, the compaction degree and strength of CSMB are often used as controlling indicators for the road to meet requirements such as bearing capacity and deformation resistance under a load of vehicles $[10,11]$.

For the test of compaction degree and strength of CSMB, the traditional methods such as the cutting ring, sand cone, water bag, and compaction meter are destructive to a certain extent and poor in efficiency and representativeness [12-14]. As a nondestructive and continuous testing tool, GPR has been widely applied in the field of civil engineering [15-17]. It is fast and economical in assessing the compaction degree, strength, and thickness of CSMB [18-21]. The interpretation and information retrieval of images of GPR-reflected waves depend on the dielectric property of CSMB, i.e., the accuracy of estimated thickness, compaction degree, strength, and moisture content depend on the dielectric constant of CSMB. Although studies of dielectric properties have been reported on reinforced concrete, cement concrete pavement, asphalt pavement, subgrade, and quarry dust stabilized lateritic soils [22-30], few studies have been conducted on the quantitative relationship between the dielectric constant and the test indicators of CSMB and the influencing factors. 
To solve the problem, groups of CSMB specimens with varying gradations and compaction degrees were collected and tested for the dielectric constants at different curing ages. The inherent relationship between the dielectric constant of CSMB and the quality indicators such as compaction degree and strength was explored. Based on the radar test data, relationship models were established between the dielectric constant and the influencing factors, including the compaction degree, moisture content, percent residues of aggregate on the sieve of maximum particle size, and curing age. The models are a theoretical basis for the application of GPR to the test and quality assessment of CSMB.

\section{The Design and Preparation of CSMB Specimens}

The mix proportion of the mass of crushed stone, sand, and cement of the CSMB specimens in this test was determined to be $60: 40: 5$ based on common practice in proportion design and the comparison and screening of compaction tests of various proportions. Two gradation types, fine and coarse, were designed for calculating the aggregate of the specimens. Percent residues of aggregate on the sieve of maximum particle size $(19 \mathrm{~mm})$ of the fine and coarse aggregate were $5 \%$ and $15 \%$, respectively. The specimens are cylinders with both diameter and height equalling $150 \mathrm{~mm}$. Specimens of each gradation type were made and grouped with different compaction degrees, including 92\%, 94\%, $96 \%, 98 \%$, and $100 \%$. There were 10 groups in all, and 16 specimens were added to each group. After stripping, 13 specimens of good quality were selected out of 16 specimens and labelled from 1 to 13 . The gradation design of the fine and coarse aggregate is as shown in Table 1 and Figure 1.

\section{Test of Relationship between the Dielectric Property and Quality Indicators}

3.1. Test of the Dielectric Constant and Strength. The dielectric constant was tested with the Swedish MALA ground-penetrating radar with an antenna frequency of $1600 \mathrm{MHz}$. A software, GroundVison, was used to test the CSMB specimens at an interval of $24 \mathrm{~h}$ for 7 days, and a signal processing software, Reflexw, was used to read the oscillographic waveforms. When data were being collected with the radar, the specimens were put on a metal plate to facilitate the pickup of the reflected radar signal. The data collection process is as shown in Figure 2.

The propagating time of the electromagnetic wave in the specimen was calculated from the oscillographic waveform collected using GPR, i.e., the time difference between the two peaks is the two-way travel time $\Delta t$ of the electromagnetic wave in the specimen. The dielectric constant could be calculated using the following equations from the two-way travel time $\Delta t$ :

$$
\begin{aligned}
v & =\frac{2 D}{\Delta t}, \\
\sqrt{\varepsilon_{r}} & =\frac{c}{v},
\end{aligned}
$$

where $D$ is the height of the CSMB specimen; $\Delta t$ is the the two-way travel time of the electromagnetic wave in the specimen; $v$ is the the propagation velocity of the electromagnetic wave; $c$ is the the propagation velocity of the electromagnetic wave in vacuum; and $\varepsilon_{r}$ is the the dielectric constant of the CSMB specimen.

The strength was tested according to Test Methods of Materials Stabilized with Inorganic Binders for Highway Engineering (JTG-E51-2009). After the curing time as stipulated in JTG-E51-2009, the specimens were tested for the unconfined compressive strength as shown in Figure 3. The average strength and the coefficient of variation met the requirements of the code, so the representative value of the unconfined compressive strength of each group of specimens was calculated according to the code.

3.2. Analysis of Test Results. Based on the aforementioned test data, the discussion here will focus on the relationship between the dielectric constant and the two indicators: the compaction degree and the unconfined compressive strength.

3.2.1. Relationship between the Dielectric Constant and the Compaction Degree. A total of 130 tests were conducted on the 10 groups of CSMB specimens, covering both types of aggregate gradations (fine and coarse) and various compaction degrees. The average value of dielectric constant of each group of specimens on the 6th day was used, as shown in Table 2().

Here are some findings from the analysis of the test data. The dielectric constant of both gradation types of CSMB specimens increases with the increase of the compaction degree. When the compaction degree is less than $96 \%$, the dielectric constant increases relatively gently with the increase of compaction degree; when the compaction degree is greater than $96 \%$, the dielectric constant obviously increases faster. The curves between the compaction degree and the dielectric constant are shown in Figures 4 and 5.

A regression analysis was carried out between the compaction degree and the dielectric constant based on the test data to more truly and accurately reflect the relationship between the compaction degree and the dielectric constant of both gradation types of CSMB specimens. Logarithmic functions were used to fit the relationship between the compaction degree and the dielectric constant, and the coefficient of determination was used for evaluation.

There is a good logarithmic relationship between the dielectric constant and compaction degree of both gradation types of CSMB specimens, and the relationship is approximately linear when the compaction degree is greater than 94\%. For the fine CSMB specimens, the relationship between the dielectric constant and the compaction degree could be fitted as shown in the following function with $R^{2}=0.88216$ : $y=98.04765+3.40204 \cdot \ln (x-6.36132)$. For the coarse CSMB specimens, the relationship between the dielectric constant and the compaction degree could be fitted nonlinearly as shown in the following function with $R^{2}=0.99818: y=97.18744+5.62846 \cdot \ln (x-6.59292)$. As 
TABLE 1: Gradation of aggregate.

\begin{tabular}{lcccccccccccc}
\hline & \multicolumn{10}{c}{ Percent of mass passing the sieve } \\
\hline Sieve size (mm) & 26.5 & 19 & 16 & 13.2 & 9.5 & 4.75 & 2.36 & 1.18 & 0.6 & 0.3 & 0.15 & 0.075 \\
Fine (\%) & 100 & 95 & 85 & 75 & 60 & 40 & 25 & 18 & 10 & 8 & 5 & 4 \\
Coarse (\%) & 100 & 85 & 75 & 70 & 50 & 40 & 25 & 18 & 10 & 8 & 5 & 4 \\
\hline
\end{tabular}

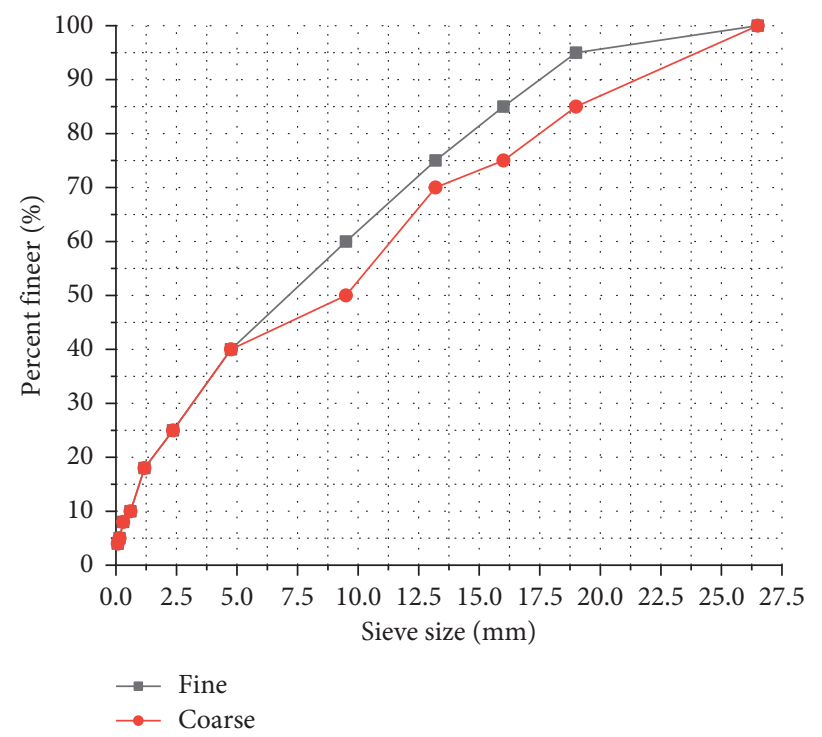

FIGURE 1: Grading curves of fine and coarse aggregate.

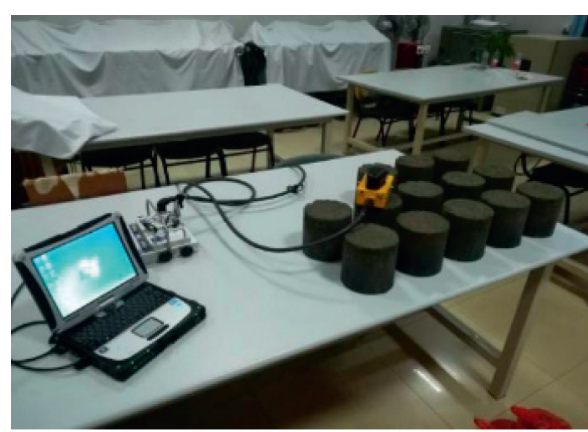

(a)

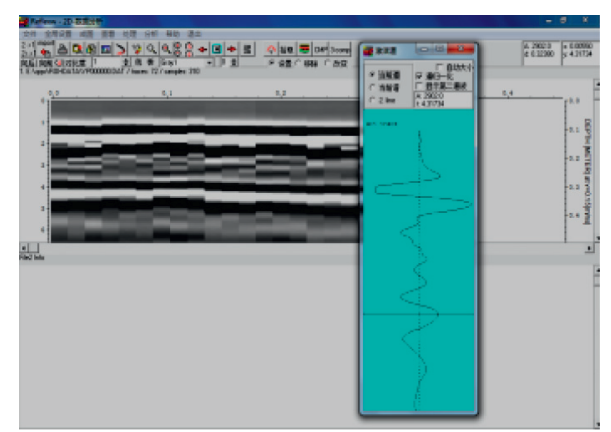

(b)

FIGURE 2: Collection of the dielectric property data of the CSMB specimens.

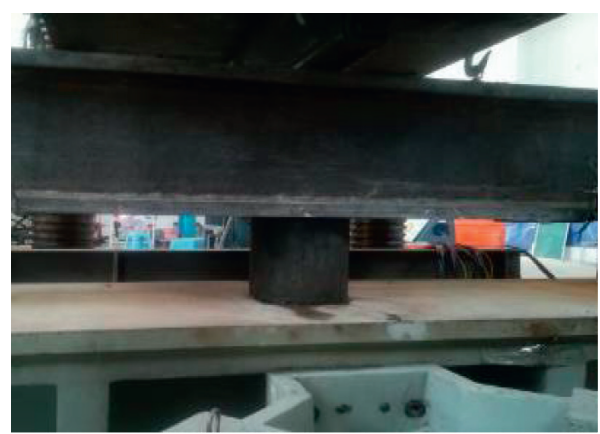

(a)

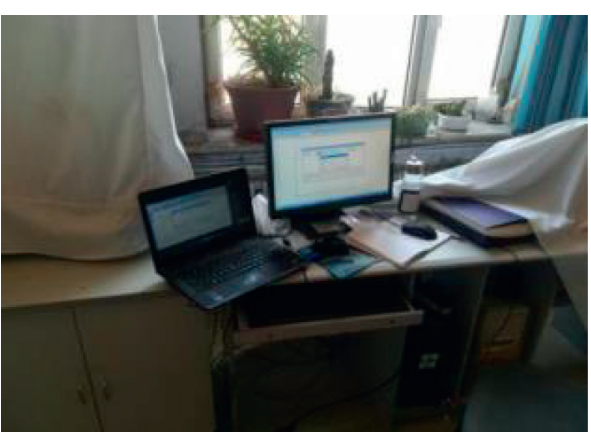

(b)

FIGURE 3: Unconfined compressive strength test of a CSMB specimen. 
TABle 2: Average dielectric constant of specimens with both gradation types and various compaction degrees.

\begin{tabular}{lccccc}
\hline Compaction degree (\%) & 92 & 94 & 96 & 98 & 100 \\
\hline Fine & 6.5277 & 6.7920 & 6.7883 & 7.2237 & 8.2306 \\
Coarse & 6.9883 & 7.1741 & 7.3842 & 7.7526 & 8.2445 \\
\hline
\end{tabular}

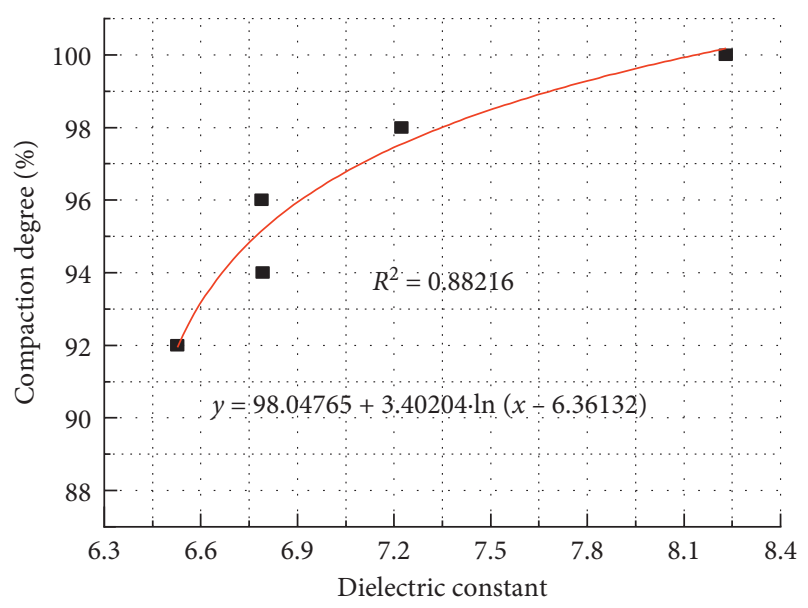

Figure 4: Relationship between the compaction degree and the dielectric constant of fine specimens.

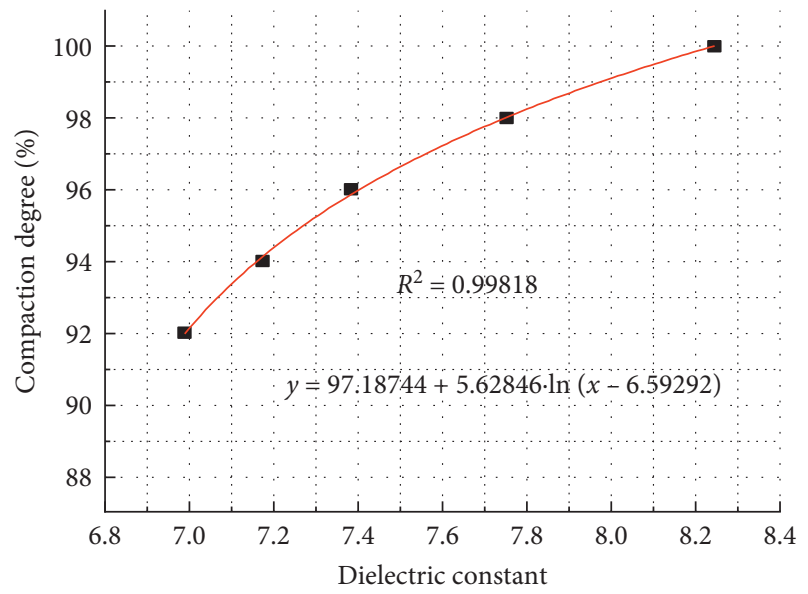

FIGURE 5: Relationship between the compaction degree and the dielectric constant of coarse specimens.

the functions fit well between the dielectric constant and the compaction degree with the coefficient of determination greater than 0.88 for both gradation types, the compaction degree can be calculated based on the dielectric constant of CSMB.

3.2.2. The Relationship between the Dielectric Constant and Strength. Curves between the dielectric constant and the unconfined compressive strength for both the fine and coarse CSMB specimens are plotted and shown in Figures 6 and 7 based on the test data from groups of specimens.

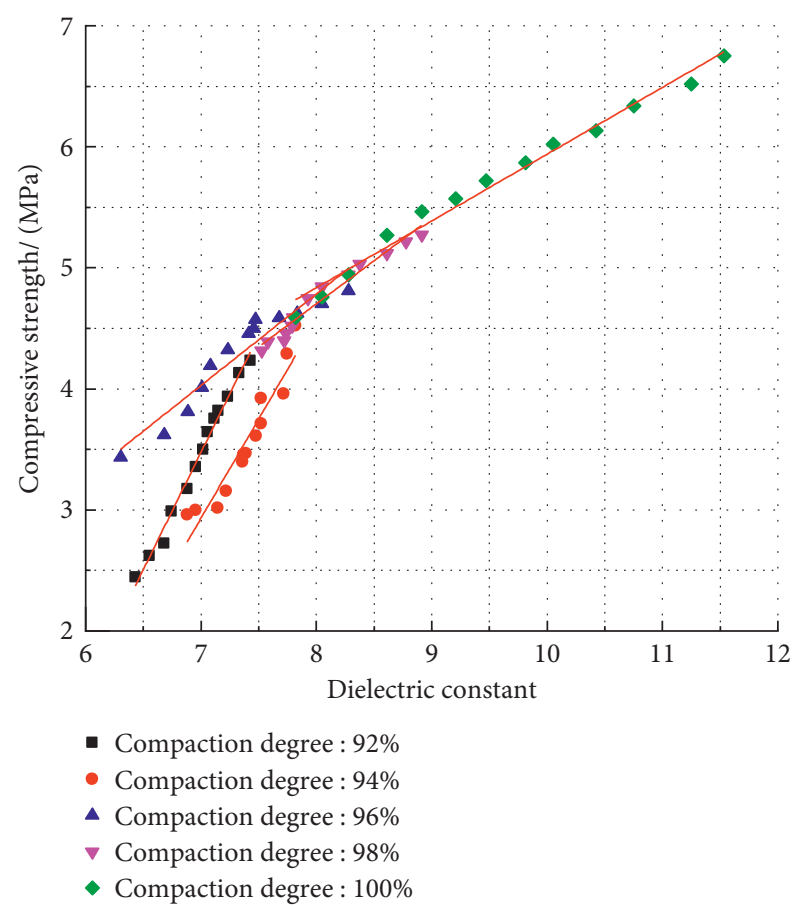

Figure 6: Relationship between the dielectric constant and strength of fine specimens.

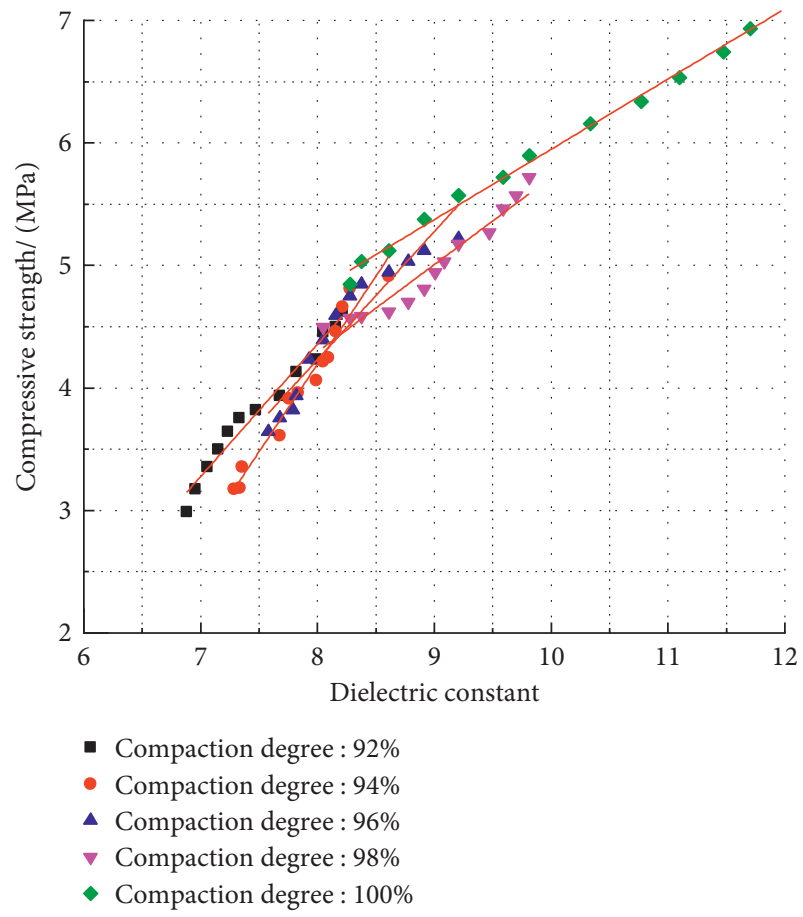

FIGURE 7: Relationship between the dielectric constant and strength of coarse specimens.

For both types of aggregate gradation of CSMB specimens, the functions were obtained by linearly fitting the relationship curves between the dielectric constant and the unconfined compressive strength of various compaction 
degrees and are shown in Table 3 with the corresponding coefficients of determination.

It can be discovered from the table that the fitted functions are a good representation of the relationship between dielectric constant and unconfined compressive strength since the coefficients of determination, the average of which is 0.95 , are greater than 0.89 in all conditions for both gradation types of CSMB. As a result, the dielectric constant of CSMB can be used to calculate and analyse the strength, which provides a theoretical basis for the GPRbased strength test in road engineering.

\section{Establishment of the Multiple Linear Regression Equations}

The relationship between the dielectric constant and certain variable, although not completely linear as shown in the single-variable functions, can be approximated as linear. For the ease of analysis and application, multivariate regression equations will be established here by applying the multiple linear regression models and the significance test and the error analysis will be conducted later.

4.1. Multiple Linear Regression Analysis of the Influencing Factors. The compaction degree, moisture content, percent residues of aggregate on the sieve of maximum particle size, curing age, and the dielectric constant are denoted as $x_{1}, x_{2}$, $x_{3}, x_{4}$, and $y$, respectively, to conduct the regression analysis. The percent residues of aggregate on the sieve of maximum particle size are $5 \%$ and $15 \%$ for the fine and coarse aggregate, respectively. The test data are as shown in Table 4 .

The following equation is assumed to correlate the independent variables $\left(x_{1}, x_{2}, x_{3}\right.$, and $\left.x_{4}\right)$ and the dependent variable:

$$
y=a_{0}+a_{1} x_{1}+a_{2} x_{2}+a_{3} x_{3}+a_{4} x_{4},
$$

where $a_{0}, a_{1}, a_{2}, a_{3}$, and $a_{4}$ is the undetermined coefficients of the equation, $x_{1}, x_{2}, x_{3}$, and $x_{4}$ is the variables of the influencing factors, and $y$ is the dielectric constant of the CSMB.

Least square estimation of the regression coefficients:

Assume the estimator of $y_{i}$ to be:

$$
y_{i}^{\prime}=a_{0}+a_{1} x_{i 1}+a_{2} x_{i 2}+a_{3} x_{i 3}+a_{4} x_{i 4} .
$$

Let

$$
Q\left(a_{0}, a_{1}, a_{2}, a_{3}, a_{4}\right)=
$$
$\sum_{i=1}^{n}\left(y_{i}-a_{0}-a_{1} x_{i 1}-a_{2} x_{i 2}-a_{3} x_{i 3}-a_{4} x_{i 4}\right)^{2}$, the least square estimators $a_{0}^{\prime}, a_{1}^{\prime}, a_{2}^{\prime}, a_{3}^{\prime}$, and $a_{4}^{\prime}$ of $a_{0}, a_{1}, a_{2}, a_{3}$, and $a_{4}$ satisfy $Q\left(a_{0}^{\prime}, a_{1}^{\prime}, a_{2}^{\prime}, a_{3}^{\prime}, a_{4}^{\prime}\right)=\min _{b_{i} 0<i<n} Q\left(a_{0}, a_{1}, a_{2}, a_{3}, a_{4}\right)$.

Solve the multivariate function by extremum method:

$$
\begin{aligned}
& \frac{\partial Q}{\partial a_{0}}=-2 \sum_{i=1}^{n}\left(y_{i}-a_{0}-a_{1} x_{i 1}-a_{2} x_{i 2}-a_{3} x_{i 3}-a_{4} x_{i 4}\right)=0, \\
& \frac{\partial Q}{\partial a_{j}}=-2 \sum_{i=1}^{n}\left(y_{i}-a_{0}-a_{1} x_{i 1}-a_{2} x_{i 2}-a_{3} x_{i 3}-a_{4} x_{i 4}\right) x_{i j}=0, \quad(j=1,2,3,4) .
\end{aligned}
$$

Reorganize the above functions to get

$$
\begin{gathered}
a_{0} n+a_{1} \sum_{i=1}^{n} x_{i 1}+a_{2} \sum_{i=1}^{n} x_{i 2}+a_{3} \sum_{i=1}^{n} x_{i 3}+a_{4} \sum_{i=1}^{n} x_{i 4}=\sum_{i=1}^{n} y_{i}, \\
a_{0} \sum_{i=1}^{n} x_{i 1}+a_{1} \sum_{i=1}^{n} x_{i 1}^{2}+a_{2} \sum_{i=1}^{n} x_{i 1} x_{i 2}+a_{3} \sum_{i=1}^{n} x_{i 1} x_{i 3}+a_{4} \sum_{i=1}^{n} x_{i 1} x_{i 4}=\sum_{i=1}^{n} x_{i 1} y_{i}, \\
a_{0} \sum_{i=1}^{n} x_{i 2}+a_{1} \sum_{i=1}^{n} x_{i 2} x_{i 1}+a_{2} \sum_{i=1}^{n} x_{i 2}^{2}+a_{3} \sum_{i=1}^{n} x_{i 2} x_{i 3}+a_{4} \sum_{i=1}^{n} x_{i 2} x_{i 4}=\sum_{i=1}^{n} x_{i 2} y_{i}, \\
a_{0} \sum_{i=1}^{n} x_{i 3}+a_{1} \sum_{i=1}^{n} x_{i 3} x_{i 1}+a_{2} \sum_{i=1}^{n} x_{i 3} x_{i 2}+a_{3} \sum_{i=1}^{n} x_{i 3}^{2}+a_{4} \sum_{i=1}^{n} x_{i 3} x_{i 4}=\sum_{i=1}^{n} x_{i 3} y_{i}, \\
a_{0} \sum_{i=1}^{n} x_{i 4}+a_{1} \sum_{i=1}^{n} x_{i 4} x_{i 1}+a_{2} \sum_{i=1}^{n} x_{i 4} x_{i 2}+a_{3} \sum_{i=1}^{n} x_{i 4} x_{i 3}+a_{4} \sum_{i=1}^{n} x_{i 4}^{2}=\sum_{i=1}^{n} x_{i 4} y_{i} .
\end{gathered}
$$


TABLE 3: Relationship between the dielectric constant and strength of CSMB specimens.

\begin{tabular}{cccccc}
\hline & $\begin{array}{c}\text { Compaction degree } \\
(\%)\end{array}$ & $\begin{array}{c}\text { Average compressive strength } \\
(\mathrm{MPa})\end{array}$ & $\begin{array}{c}\text { Average dielectric } \\
\text { constant }\end{array}$ & $\begin{array}{c}\text { Coefficient of } \\
\text { determination }\end{array}$ & Fitted function \\
\hline \multirow{4}{*}{ Fine } & 92 & 3.41086 & 6.96593 & 0.98779 & $y=1.93949 x-10.09946$ \\
& 94 & 3.57645 & 7.39290 & 0.89631 & $y=1.63837 x-8.53587$ \\
& 96 & 4.28175 & 7.33488 & 0.90873 & $y=0.75539 x-1.25895$ \\
& 98 & 4.76155 & 8.08176 & 0.95765 & $y=0.71106 x-0.98507$ \\
Coarse & 100 & 5.69127 & 9.55040 & 0.98272 & $y=0.5517 x+0.42231$ \\
& 92 & 3.85619 & 7.53608 & 0.97117 & $y=1.07955 x-4.27938$ \\
& 94 & 4.04465 & 7.89399 & 0.95968 & $y=1.43268 x-7.26491$ \\
& 96 & 4.48533 & 8.24218 & 0.90271 & $y=1.0446 x-4.12449$ \\
& 100 & 4.99977 & 8.98902 & 0.93418 & $y=0.71186 x-1.39918$ \\
& & 5.95318 & 10.00861 & 0.99453 & $y=0.57335 x+0.21475$ \\
\hline
\end{tabular}

TABLE 4: Summary of the measured dielectric constant and the influencing factors.

\begin{tabular}{|c|c|c|c|c|c|c|c|c|c|c|c|c|}
\hline & \multicolumn{6}{|c|}{ Fine } & \multicolumn{6}{|c|}{ Coarse } \\
\hline Compaction degree (\%) & \multicolumn{6}{|c|}{92} & \multicolumn{6}{|c|}{92} \\
\hline Moisture content & \multicolumn{6}{|c|}{0.3767} & \multicolumn{6}{|c|}{0.3767} \\
\hline Age (d) & 1 & 2 & 3 & 4 & 5 & 6 & 1 & 2 & 3 & 4 & 5 & 6 \\
\hline Dielectric constant & 7.7588 & 7.1016 & 6.9208 & 6.8057 & 6.6811 & 6.5277 & 8.6183 & 7.7243 & 7.4190 & 7.2828 & 7.1838 & 6.9883 \\
\hline Compaction degree (\%) & \multirow{2}{*}{\multicolumn{6}{|c|}{$\begin{array}{c}94 \\
0.3849\end{array}$}} & \multirow{2}{*}{\multicolumn{6}{|c|}{$\begin{array}{c}94 \\
0.3849\end{array}$}} \\
\hline Moisture content & & & & & & & & & & & & \\
\hline Age $(d)$ & 1 & 2 & 3 & 4 & 5 & 6 & 1 & 2 & 3 & 4 & 5 & 6 \\
\hline Dielectric constant & 8.5153 & 7.7825 & 7.2677 & 7.0846 & 6.9153 & 6.7920 & 9.0631 & 8.2387 & 7.7721 & 7.6402 & 7.4757 & 7.1741 \\
\hline Compaction degree (\%) & \multirow{2}{*}{\multicolumn{6}{|c|}{$\begin{array}{c}96 \\
0.3931\end{array}$}} & \multirow{2}{*}{\multicolumn{6}{|c|}{$\begin{array}{c}96 \\
0.3931\end{array}$}} \\
\hline Moisture content & & & & & & & & & & & & \\
\hline Age $(d)$ & 1 & 2 & 3 & 4 & 5 & 6 & 1 & 2 & 3 & 4 & 5 & 6 \\
\hline Dielectric constant & 8.4092 & 7.5303 & 7.2155 & 7.0899 & 6.9761 & 6.7883 & 9.3001 & 8.6650 & 8.3424 & 7.9857 & 7.7758 & 7.3842 \\
\hline Compaction degree (\%) & \multirow{2}{*}{\multicolumn{6}{|c|}{$\begin{array}{c}98 \\
0.4013\end{array}$}} & \multirow{2}{*}{\multicolumn{6}{|c|}{$\begin{array}{c}98 \\
0.4013\end{array}$}} \\
\hline Moisture content & & & & & & & & & & & & \\
\hline Age $(d)$ & 1 & 2 & 3 & 4 & 5 & 6 & 1 & 2 & 3 & 4 & 5 & 6 \\
\hline Dielectric constant & 8.9784 & 8.4951 & 8.2843 & 7.8525 & 7.6565 & 7.2237 & 10.1826 & 9.6602 & 9.2539 & 8.7755 & 8.3131 & 7.7527 \\
\hline Compaction degree (\%) & \multicolumn{6}{|c|}{100} & \multicolumn{6}{|c|}{100} \\
\hline Moisture content & \multicolumn{6}{|c|}{0.4095} & \multicolumn{6}{|c|}{0.4095} \\
\hline Age $(d)$ & 1 & 2 & 3 & 4 & 5 & 6 & 1 & 2 & 3 & 4 & 5 & 6 \\
\hline Dielectric constant & 11.0060 & 10.2592 & 9.8818 & 9.1211 & 8.8037 & 8.2306 & 11.5723 & 10.8844 & 10.3793 & 9.8995 & 9.0737 & 8.2445 \\
\hline
\end{tabular}

Solve the above equations and let

$$
\begin{aligned}
\bar{y} & =\frac{1}{n} \sum_{i=1}^{n} y_{i} \\
\bar{x}_{j} & =\frac{1}{n} \sum_{i=1}^{n} x_{i j}, \quad(j=1,2,3,4) .
\end{aligned}
$$

Then (5) can be simplified as

$$
a_{0}=\bar{y}-a_{1} \bar{x}_{1}-a_{2} \bar{x}_{2}-a_{3} \bar{x}_{3}-a_{4} \bar{x}_{4} .
$$

Substitute into (5)-(7) and (11), (9) respectively, and simplify it to obtain 


$$
\begin{aligned}
L_{11} a_{1}+L_{12} a_{2}+L_{13} a_{3}+L_{14} a_{4} & =L_{1 y}, \\
L_{21} a_{1}+L_{22} a_{2}+L_{23} a_{3}+L_{24} a_{4}= & L_{2 y}, \\
L_{31} a_{1}+L_{32} a_{2}+L_{33} a_{3}+L_{34} a_{4}= & L_{3 y}, \\
L_{41} a_{1}+L_{42} a_{2}+L_{43} a_{3}+L_{44} a_{4}= & L_{4 y}, \\
L_{j k}= & \sum_{i=1}^{n}\left(x_{i j}-\bar{x}_{j}\right)\left(x_{i k}-\bar{x}_{k}\right)=\sum_{i=1}^{n} x_{i j} x_{i k}-\frac{1}{n} \sum_{i=1}^{n} x_{i j} \sum_{i=1}^{n} x_{i k}, \\
L_{j y}= & \sum_{i=1}^{n}\left(x_{i j}-\bar{x}_{j}\right)\left(y_{i}-\bar{y}\right)=\sum_{i=1}^{n} x_{i j} y_{i}-\frac{1}{n} \sum_{i=1}^{n} x_{i j} \sum_{i=1}^{n} y_{i}, \\
& (j=1,2,3,4 ; k=1,2,3,4) .
\end{aligned}
$$

$L_{j k}$ and $L_{j y}$ can be figured out based on the table of test data. The equations can be expressed in matrix form as

$$
\left[\begin{array}{cccc}
480 & 1.968 & 0 & 0 \\
1.968 & 0.0080688 & 0 & 0 \\
0 & 0 & 1500 & 0 \\
0 & 0 & 0 & 175
\end{array}\right] \cdot\left[\begin{array}{l}
a_{1} \\
a_{2} \\
a_{3} \\
a_{4}
\end{array}\right]=\left[\begin{array}{c}
142.79 \\
0.58542614 \\
100.35 \\
-66.5744
\end{array}\right]
$$

Solve the matrix equations to get

$$
\left[\begin{array}{l}
a_{1} \\
a_{2} \\
a_{3} \\
a_{4}
\end{array}\right]=\left[\begin{array}{c}
0.295039 \\
0.595238 \\
0.0669 \\
-0.380425
\end{array}\right]
$$

The average value of compaction degree, moisture content, percent residues of aggregate on the sieve of maximum particle size, curing age, and the dielectric constant were figured out to be 96, 0.3931, 10, 3.5, and 8.1996767 , respectively, from the test data in Table 4 . The values of the variables were substituted in (11) to obtain the value of $a_{0}=-19.695568$. So the final comprehensive equation between the dielectric constant and the influencing factors of the CSMB is

$$
\begin{aligned}
y= & -19.695568+0.295039 x_{1}+0.595238 x_{2}+0.0669 x_{3} \\
& -0.380425 x_{4} .
\end{aligned}
$$

It can be seen directly from the regression (15) that the variation of the dielectric constant is consistent with the conclusions above when one of the influencing factors of the CSMB changes, which includes the compaction degree, the moisture content, percent residues of aggregate on the sieve of maximum particle size, and curing age.

\subsection{Significance Test}

4.2.1. Hypothesis Test. Hypothesis H0: all the undetermined coefficients in the comprehensive tests (2) are 0.
The linear relationship between the independent variables and dependent variable in (15) would be appropriate if the hypothesis is rejected.

The value of $F$, which is the testing statistic of the hypothesis, could be figured out from the test data in Table 4 . The value of $F$ is compared with $F \alpha(m, n-m-1)$ at the onesided percentile $\alpha$, which is the given significance level $(0<\alpha<1)$. The regression equation is significant if $F>F \alpha$ $(m, n-m-1)$, i.e., there is a significant linear relationship between the independent variables and the dependent variable at the significance level of $\alpha$. Otherwise, the regression equation is not significant, and the linear relationship between the independent variables and the dependent variable is inappropriate.

$$
\begin{aligned}
S_{\mathrm{SR}} & =\sum_{i=1}^{n}\left(y_{i}-y_{i}^{\prime}\right)^{2} S_{\mathrm{SE}}=\sum_{i=1}^{n}\left(y_{i}^{\prime}-\bar{y}\right)^{2}, \\
F & =\frac{S_{\mathrm{SE}} / m}{S_{\mathrm{SR}} /(n-m-1)} \sim F(m, n-m-1) .
\end{aligned}
$$

The test data from Table 4 were substituted into the above equations to calculate the results, which are shown in Table 5.

4.2.2. Error Analysis. To analyse the errors of the comprehensive equation, $60 \mathrm{CSMB}$ specimens with different compaction degrees, moisture contents, percent residues of coarse aggregate on the sieve of maximum particle size, and curing ages were collected and tested for the dielectric constant. The test results and the calculated results by the comprehensive multiple linear regression equation were compared, and the resulting data and curves are as shown in Table 6 and Figure 8.

The sum of squares of residual values is used to evaluate the goodness of fit of a group of data. The smaller the sum of squares of residuals, the better the goodness of fit of the data, and vice versa. The sum of squares of residuals between the test results and the calculated results, figured out according to the equation of sum of squares of residuals, is 10.2089 , indicating a good agreement between the test results and the 
TABLE 5: Summary of variables of the significance test.

\begin{tabular}{lcccccc}
\hline Variables & $n$ & $m$ & $S_{\mathrm{SE}}$ & $S_{\mathrm{SR}}$ & $F$ & $F_{0.01}(4,55)$ \\
\hline Values & 60 & 4 & 74.5171 & 10.2089 & 100.3733 & 3.695 \\
\hline
\end{tabular}

The comprehensive multivariate equation of the dielectric constant is highly significant since the variable $F=100.3733$ in the table is much greater than $F_{0.01}$ $(4,55)=3.695$.

TABLE 6: Summary of the test results and calculated results by the comprehensive equation of dielectric constant.

\begin{tabular}{|c|c|c|c|c|c|c|c|}
\hline No. & Calculated & Test & Error (test-calculated) & No. & Calculated & Test & Error (test-calculated) \\
\hline 1 & 7.6263 & 7.7588 & 0.1325 & 31 & 9.4852 & 9.3001 & -0.1851 \\
\hline 2 & 7.2459 & 7.1016 & -0.1443 & 32 & 9.1048 & 8.665 & -0.4398 \\
\hline 3 & 6.8655 & 6.9208 & 0.0553 & 33 & 8.7244 & 8.3424 & -0.3820 \\
\hline 4 & 6.4850 & 6.8057 & 0.3207 & 34 & 8.3440 & 7.9857 & -0.3583 \\
\hline 5 & 6.1046 & 6.6811 & 0.5765 & 35 & 7.9635 & 7.7758 & -0.1877 \\
\hline 6 & 5.7242 & 6.5277 & 0.8035 & 36 & 7.5831 & 7.3842 & -0.1989 \\
\hline 7 & 8.2953 & 8.6183 & 0.3230 & 37 & 9.4112 & 8.9784 & -0.4328 \\
\hline 8 & 7.9149 & 7.7243 & -0.1906 & 38 & 9.0308 & 8.4951 & -0.5357 \\
\hline 9 & 7.5345 & 7.419 & -0.1155 & 39 & 8.6503 & 8.2843 & -0.3660 \\
\hline 10 & 7.1540 & 7.2828 & 0.1288 & 40 & 8.2699 & 7.8525 & -0.4174 \\
\hline 11 & 6.7736 & 7.1838 & 0.4102 & 41 & 7.8895 & 7.6565 & -0.2330 \\
\hline 12 & 6.3932 & 6.9883 & 0.5951 & 42 & 7.5091 & 7.2237 & -0.2854 \\
\hline 13 & 8.2213 & 8.5153 & 0.2940 & 43 & 10.0802 & 10.1826 & 0.1024 \\
\hline 14 & 7.8409 & 7.7825 & -0.0584 & 44 & 9.6998 & 9.6602 & -0.0396 \\
\hline 15 & 7.4604 & 7.2677 & -0.1927 & 45 & 9.3193 & 9.2539 & -0.0654 \\
\hline 16 & 7.0800 & 7.0846 & 0.0046 & 46 & 8.9389 & 8.7755 & -0.1634 \\
\hline 17 & 6.6996 & 6.9153 & 0.2157 & 47 & 8.5585 & 8.3131 & -0.2454 \\
\hline 18 & 6.3192 & 6.792 & 0.4728 & 48 & 8.1781 & 7.7527 & -0.4254 \\
\hline 19 & 8.8903 & 9.0631 & 0.1728 & 49 & 10.0062 & 11.006 & 0.9998 \\
\hline 20 & 8.5099 & 8.2387 & -0.2712 & 50 & 9.6257 & 10.2592 & 0.6335 \\
\hline 21 & 8.1294 & 7.7721 & -0.3573 & 51 & 9.2453 & 9.8818 & 0.6365 \\
\hline 22 & 7.7490 & 7.6402 & -0.1088 & 52 & 8.8649 & 9.1211 & 0.2562 \\
\hline 23 & 7.3686 & 7.4757 & 0.1071 & 53 & 8.4845 & 8.8037 & 0.3192 \\
\hline 24 & 6.9882 & 7.1741 & 0.1859 & 54 & 8.1040 & 8.2306 & 0.1266 \\
\hline 25 & 8.8162 & 8.4092 & -0.4070 & 55 & 10.6752 & 11.5723 & 0.8971 \\
\hline 26 & 8.4358 & 7.5303 & -0.9055 & 56 & 10.2947 & 10.8844 & 0.5897 \\
\hline 27 & 8.0554 & 7.2155 & -0.8399 & 57 & 9.9143 & 10.3793 & 0.4650 \\
\hline 28 & 7.6750 & 7.0899 & -0.5851 & 58 & 9.5339 & 9.8995 & 0.3656 \\
\hline 29 & 7.2945 & 6.9761 & -0.3184 & 59 & 9.1535 & 9.0737 & -0.0798 \\
\hline 30 & 6.9141 & 6.7883 & -0.1258 & 60 & 8.7730 & 8.2445 & -0.5285 \\
\hline
\end{tabular}

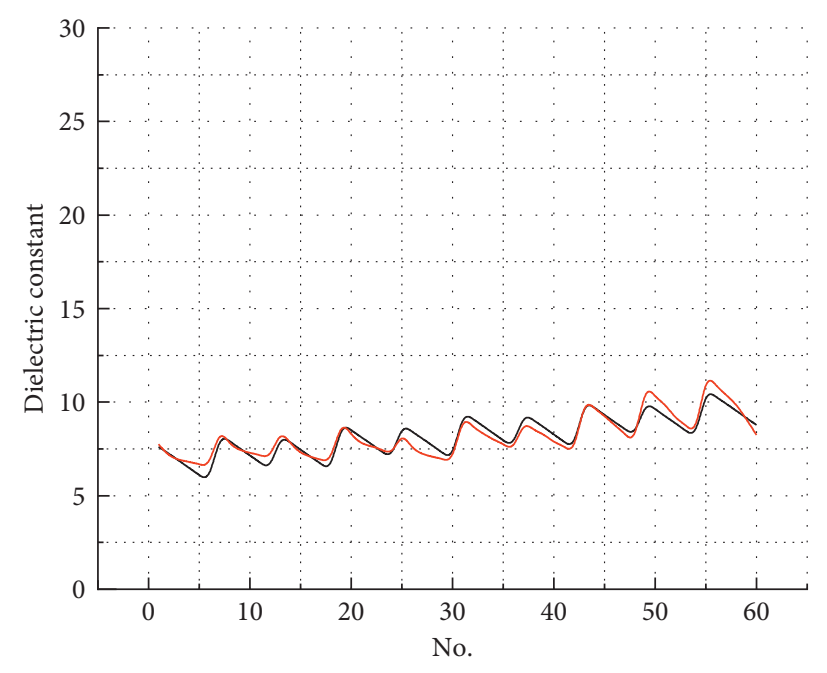

Calculated value by the

comprehensive equation

— Test value

FIGURE 8: Comparison between the test results and calculated results using the comprehensive equation of the dielectric constant. 
calculated test results by the comprehensive equation of the dielectric constant of CSMB.

\section{Conclusions}

Groups of fine or coarse CSMB specimens were designed, produced, and tested. The relationship between the dielectric constant of CSMB and the influencing factors such as the compaction degree, moisture content, percent residues of aggregate on the sieve of maximum particle size, and curing age, and the relationship between the dielectric constant and the unconfined compressive strength were investigated based on a number of test data and theoretical analysis. The main conclusions are as follows.

(1) There was a good logarithmic relationship between the dielectric constant and the compaction degree of both gradation types of CSMB, and the relationship is approximately linear when the compaction degree is greater than 94\%. Quantitative functions have been established between the dielectric constant and the compaction degree of CSMB, which can be used for the engineering calculation of compaction degree based on the dielectric constant.

(2) There is a linear relationship between the dielectric constant and the unconfined compressive strength of both the fine and coarse CSMB. Quantitative functions have been established between the dielectric constant and the unconfined compressive strength of CSMB, which can be used for the engineering calculations of strength, based on the dielectric constant.

(3) A comprehensive equation between the dielectric constant of CSMB and the influencing factors such as the compaction degree, moisture content, percent residues of aggregate on the sieve of maximum particle size, and curing age has been established on the basis of the test data. The equation, validated with high significance and small error, can be used for the engineering calculations of unknown variables that cannot be tested directly based on the dielectric constant and other known variables [30].

\section{Data Availability}

The data are available and explained in this article; readers can access the data supporting the conclusions of this study.

\section{Conflicts of Interest}

Authors declare no conflicts of interest. The manuscript is approved by all authors for publication. The authors would like to declare on behalf of all co-authors that the work described is original research and has not been published previously.

\section{Acknowledgments}

This work was supported by the Heilongjiang Provincial Natural Science Fund (E201462).

\section{References}

[1] R. J. Galley, M. Trachtenberg, A. Langlois, D. G. Barber, and L. Shafai, "Observations of geophysical and dielectric properties and ground penetrating radar signatures for discrimination of snow, sea ice and freshwater ice thickness," Cold Regions Science and Technology, vol. 57, no. 1, 2009.

[2] J. Lai, Y. Xu, X. Zhang, Q. Yan, M. Xu, B. Zhou, and D. Zhao, Comparison of dielectric properties and structure of lunar regolith at chang'e- 3 and chang'e- 4 landing sites revealed by ground-penetrating radar," Geophysical Research Letters, vol. 46 , no. 22, 2019.

[3] M. Mastrogiuseppe, A. G. Hayes, V. Poggiali et al., "Bathymetry and composition of Titan's Ontario Lacus derived from Monte Carlo-based waveform inversion of Cassini RADAR altimetry data," Icarus, vol. 300, 2018.

[4] W. AzizatunAzimmah, "Analysis of ground penetrating radar's capability for detecting underground cavities: a case study in Japan cave of taman hutan raya bandung," IOP Conference Series: Earth and Environmental Science, vol. 62, no. $1,2017$.

[5] C. Gouramanis, A. D. Switzer, D. T. Pham, C. S. Bristow, and K. Jankaew, C. M. Rubin, Y. S. Lee, S. R. Ildefonso, and H. M. Jol, Ground penetrating radar examination of thin tsunami beds-a case study from Phra Thong Island, Thailand," Sedimentary Geology, vol. 329, 2015.

[6] A. D. M. ElenaPettinelli, B. Stanley Eugene, L. Sebastian Emanuel, and G. Alessandro, "A controlled experiment to investigate the correlation between early-time signal attributes of ground-coupled radar and soil dielectric properties," Journal of Applied Geophysics, vol. 101, 2014.

[7] N. Gagarin and J. Mekemson, "Step-frequency ground-penetrating-radar array calibration requirements to estimate dielectric properties of pavements," Near Surface Geophysics, vol. 14, no. 2, pp. 105-115, 2016.

[8] Y. Zhong, Y. Wang, B. Zhang et al., "Prediction model of asphalt content of asphalt mixture based on dielectric properties," Advances in Civil Engineering, vol. 2020, Article ID 6661593, 10 pages, 2020.

[9] A. K. Khamzin, A. V. Varnavina, E. V. Torgashov, and N. L. Anderson, L. H. Sneed, Utilization of air-launched ground penetrating radar (GPR) for pavement condition assessment," Construction and Building Materials, vol. 141, 2017.

[10] D. S. Feng and Q. W. Dai, "Application of ground penetrating radar in the survey of the pavement thickness in highway," Progress in Geophysics, vol. 23, no. 1, pp. 289-294, 2008.

[11] M. Wu, Application of Ground Penetrating Radar for Asphalt Pavement Detection, Chang'an University, Chang'an, China, 2014.

[12] Y. Zhang, An experiment Study of the Dielectric Properties of the Structural Materials of pavement, Vol. 5, Zhengzhou University, , Zhengzhou, China, 2005.

[13] GuoChengchao, Inversion of Dielectric Properties of Pavement Structural Materials and Application of Pavement Radar, Zhengzhou University, Zhengzhou, China, 2004.

[14] T. Wang, Study on Dielectric Properties and Composite Dielectric Model of cementconcrete, Zhengzhou University, Zhengzhou, China, 2011.

[15] V. M. Malhotra and N. J. Carino, Eds., Handbook on NondestructiveTestingof Concrete, CRC Press, Boca Raton, FL, USA, 2nd edition, 2006. 
[16] A. P. Annan, Ground Penetrating Radar: Principles, Procedures \& Applications, Sensors \& Softwares Inc, Mississauga, 2004.

[17] D. J. Daniels, Ed., Ground Penetrating Radar, The Institution of ElectricalEngineers, London, UK, 2nd edition, 2004.

[18] S. Kashif Ur Rehman, Z. Ibrahim, S. A. Memon, and M. Jameel, "Nondestructive test methods for concrete bridges: a review," Construction and Building Materials, vol. 107, pp. 58-86, 2016.

[19] D. Goulias and M. L. Scott, Effective Implementation of Ground Penetrating Radar (GPR) for Condition Assessment \& Monitoring of Critical InfrastructureComponents of Bridges and Highways, p. 183, 2015.

[20] J. Stryk, A. M. Alani, R. Matula, and K. Pospisil, Innovative Inspection Procedures for Effective GPR Surveying of Critical Transport Infrastructures (Pavements, Bridges and Tunnels), Springer International Publishing, New York, NY, USA, 2015.

[21] A. V. Varnavina, A. K. Khamzin, E. V. Torgashov, L. H. Sneed, B. T. Goodwin, and N. L. Anderson, "Data acquisition and processing parameters for concrete bridge deck condition assessment using ground-coupled ground penetrating radar: some considerations," Journal of Applied Geophysics, vol. 114, pp. 123-133, 2015.

[22] F. Hong and D. Chen, "Evaluation of asphalt overlay permanent deformation based on ground-penetrating radar technology," Journal of Testing and Evaluation, vol. 44, no. 4, Article ID 20130241, 2016.

[23] P. Gu and J. J. Beaudoin, "Dielectric behaviour of hardened cementitious materials," Advances in Cement Research, vol. 9, no. 33, pp. 1-8, 1997.

[24] W. L. Lai, W. F. Tsang, H. Fang, and D. Xiao, "Experimental determination of bulk dielectricproperties and porosity of porousasphalt and soils using GPR and a cyclic moisture variation technique," Geophysics, vol. 71, no. 4, pp. K93-K102, 2006.

[25] J. A. Huisman, S. S. Hubbard, J. D. Redman, and A. P. Annan, "Measuring soil water content with ground penetrating radar: a review," Vadose Zone Journal, vol. 2, no. 4, pp. 476-491, 2003.

[26] W. L. Lai, S. C. Kou, W. F. Tsang, and C. S. Poon, "Characterization of concrete properties from dielectric properties using ground penetrating radar," Cement and Concrete Research, vol. 39, no. 8, 2009.

[27] M. Istiaque Hasan and N. Yazdani, "An experimental study for quantitative estimation of rebar corrosion in concrete using ground penetrating radar," International Journal of Engineering, vol. 2016, Article ID 8536850, 2016.

[28] Y. P. Tian, D. CeHuang, and B. Li, "Monitoring early hydration of concrete with ground penetrating radar," Key Engineering Materials, vol. 4348, 2017.

[29] O. Kennedy and B. V. Duc, "Adsorbed complex and laboratory geotechnics of Quarry Dust (QD) stabilized lateritic soils," Environmental Technology \& Innovation, vol. 10, 2018.

[30] Ministry of Transport of the People's Republic of China, Test Methods of Materials Stabilized with Inorganic Binders for Highway Engineering, 2009. 